\title{
Increased expression of heat shock protein 90 under chemical hypoxic conditions protects cardiomyocytes against injury induced by serum and glucose deprivation
}

\author{
KENG WU ${ }^{1}$, WENMING XU ${ }^{2}$, QIONG YOU ${ }^{1}$, RUNMIN GUO $^{3}$, JIANQIANG FENG ${ }^{3}$, \\ CHANGRAN ZHANG $^{2}$ and WEN WU ${ }^{4}$
}

\author{
${ }^{1}$ Department of Cardiology, The Affiliated Hospital, Guangdong Medical College, Zhanjiang; \\ ${ }^{2}$ Department of Internal Medicine, Huangpu Division of The First Affiliated Hospital; \\ ${ }^{3}$ Department of Physiology, Zhongshan School of Medicine, Sun Yat-sen University; ${ }^{4}$ Department of \\ Endocrinology, Guangdong Geriatrics Institute, Guangdong General Hospital, Guangzhou, P.R. China
}

Received May 31, 2012; Accepted July 4, 2012

DOI: 10.3892/ijmm.2012.1099

\begin{abstract}
Heat shock proteins (HSPs) are critical for adaptation to hypoxia and/or ischemia. Previously, we demonstrated that cobalt chloride $\left(\mathrm{CoCl}_{2}\right)$, a well-known hypoxia mimetic agent, is an inducer of HSP90. In the present study, we tested the hypothesis that $\mathrm{CoCl}_{2}$-induced upregulation of HSP90 is able to provide cardioprotection in serum and glucose-deprived $\mathrm{H} 9 \mathrm{c} 2$ cardiomyocytes (H9c2 cells). Cell viability was detected using a CCK-8 assay, while HSP90 expression was detected via western blotting. The findings of this study showed that serum and glucose deprivation (SGD) induced significant cytotoxicity, overproduction of reactive oxygen species (ROS) and a loss of mitochondrial membrane potential (MMP) in $\mathrm{H} 9 \mathrm{c} 2$ cells. In addition, SGD downregulated the expression of HSP90 in a time-dependent manner. The selective inhibitor of HSP90 17-allylamino-17-demethoxygeldanamycin (17-AAG) aggravated SGD-induced cytotoxicity. $\mathrm{CoCl}_{2}$ at $100 \mu \mathrm{M}$ timedependently enhanced the expression of HSP90. Treatment with $\mathrm{CoCl}_{2}$ from 50 to $200 \mu \mathrm{M}$ significantly attenuated cytotoxicity and the downregulation of HSP90 expression induced by SGD for $24 \mathrm{~h}$, respectively. Notably, pretreatment of H9c2 cells with 17-AAG at $2 \mu \mathrm{M}$ for $60 \mathrm{~min}$ before exposure to both $\mathrm{CoCl}_{2}(100 \mu \mathrm{M})$ and SGD significantly blocked the $\mathrm{CoCl}_{2}-$ induced cardioprotective effect, demonstrated by decreased
\end{abstract}

Correspondence to: Professor Changran Zhang, Department of Internal Medicine, Huangpu Division of the First Affiliated Hospital, Sun Yat-sen University, Guangzhou 510700, P.R. China

E-mail: zhangchangran@yeah.net

Professor Wen Wu, Department of Endocrinology, Guangdong Geriatrics Institute, Guangdong General Hospital, Guangzhou 510080, P.R. China

E-mail: wuwengz@126.com

Key words: heat shock proteins, chemical hypoxia, cobalt chloride, serum and glucose deprivation, ischemia, cardioprotection cell viability and MMP loss, as well as increased ROS generation. Taken together, these results suggest that HSP90 may be one of the endogenous defensive mechanisms for resisting ischemia-like injury in H9c2 cells, and that HSP90 plays an important role in chemical hypoxia-induced cardioprotection against SGD-induced injury by its antioxidation and preservation of mitochondrial function.

\section{Introduction}

The cardiac oxygen-sensing mechanism has attracted extensive attention. A variety of genes relating to hypoxia adaptation are induced at low-oxygen tensions, including erythropoietin (EPO), vascular endothelial growth factor (VEGF), glycolytic enzymes, glucose transporters, heme proteins, and hypoxia inducible factor- 1 (HIF-1) in various cell types (1-4). The HIF-1 is the first identified family of transcription factors that are rapidly elicited by hypoxia by inhibition of their ubiquitindependent degradation (5). Previously, the important role of HIF-1 in the cellular mechanism of oxygen-sensing was demonstrated by confirming that the upregulation of $89 \%$ of genes induced by hypoxia is HIF-1-dependent (6). In their study, Baird et al (7) reported that heat shock proteins (HSPs) are regulated by HIF-1 during hypoxia.

It has been well documented that cobalt chloride $\left(\mathrm{CoCl}_{2}\right)$ is a well-known hypoxia mimetic agent that mimics the hypoxic response in various ways (3). $\mathrm{CoCl}_{2}$-mimicked hypoxia enhances the level of HIF-1 $\alpha$ protein (8-10). Thus, $\mathrm{CoCl}_{2}$ has been used to explore the cardiac oxygen-sensing mechanism in various experiment models. In isolated, perfused rat hearts in hypoxia/reoxygenation, prior chronic oral $\mathrm{CoCl}_{2}$ improves cardiac functions by increasing the levels of VEGF, aldolase-A, and glucose transporter-1 (11). Furthermore, $\mathrm{CoCl}_{2}$ pretreatment before prolonged deep hypothermic circulatory arrest (DHCA) rescues myocardial apoptosis by mechanisms involving the phosphorylation of Akt, upregulation of the antiapoptotic protein Bcl-2 expression and a decreased expression of the proapoptotic protein $\mathrm{Bax}$ (12). These results showed that preconditioning with $\mathrm{CoCl}_{2}$ protects against cardiac injury 
induced by hypoxia or ischemia. The clinical significance of such a strategy, however, is limited by the unpredictability of hypoxia or ischemia time. The postconditioning has been developed and has a similar effect as preconditioning in a canine model of reversible coronary occlusion (13). Since the hypoxia and/or ischemia-related diseases or injuries are clinically common, developing a new therapeutic strategy for treatment of these diseases or injuries is essential. Since cobalt has been administered to human patients for the treatment of anemia (14), and induces several hypoxia-related protective factors, such as EPO $(15,16)$, HSP90 (17) and heme oxgenase-1 (HO-1) $(18,19)$, we speculates that the co-existence of low concentrations of $\mathrm{CoCl}_{2}$ with serum and glucose deprivation (SGD) is likely to attenuate ischemia-like injury in cardiomyocytes.

To test this hypothesis, we undertook to examine the protective effect of low concentrations of $\mathrm{CoCl}_{2}$ against SGD-induced injury of H9c2 cardiomyocytes (H9c2 cells), as well as the role of HSP90 in this cardioprotection and its mechanisms. The findings of the present study have demonstrated that the co-treatment of $\mathrm{CoCl}_{2}$ significantly protects $\mathrm{H} 9 \mathrm{c} 2$ cells against SGD-induced injury. Activation of the oxygen-sensing mechanism by $\mathrm{CoCl}_{2}$ upregulates the expression of HSP90, which is an important $\mathrm{CoCl}_{2}$-induced adaptive response to the SGD condition. Such molecular adaptation to ischemia-like events may contribute to the functional improvement of cardiomyocytes, including antioxidation and the preservation of MMP.

\section{Materials and methods}

Materials. $\mathrm{CoCl}_{2}$, glucose, 17-allylamino-17-demethoxygeldanamycin (17-AAG), dichlorofluorescin diacetate (DCFH-DA) and Rhodamine 123 (Rh123) were purchased from SigmaAldrich Corporation (St. Louis, MO, USA). HSP90 antibody was purchased from Bioworld Technology (Minneapolis, MN, USA). The cell counter kit-8 (CCK-8) was purchased from Dojindo Laboratories (Kyushu, Japan). Glucose-free DMEM medium and fetal bovine serum (FBS) were supplied by Gibco-BRL (Calsbad, CA, USA).

Cell culture and treatments. H9c2 cells were obtained from Sun Yat-sen University Experimental Animal Centre (Guangzhou, China). The H9c2 cell line, a subclone of the original clonal cell line, was derived from embryonic rat heart tissue. The cells were cultured in DMEM medium supplemented with normal glucose $(5.5 \mathrm{mM})$ and $15 \% \mathrm{FBS}$ at $37^{\circ} \mathrm{C}$ under an atmosphere of $5 \% \mathrm{CO}_{2}$ and $95 \%$ air.

$\mathrm{H} 9 \mathrm{c} 2$ cells were incubated in glucose- and FBS-free DMEM medium to set up a model of SGD and mimic ischemia-induced cardiac injury. $\mathrm{CoCl}_{2}$ was added into the above DMEM medium to examine its cytoprotective effects. The selective HSP90 inhibitor, 17-AAG, was administered for $60 \mathrm{~min}$ prior to exposure of the $\mathrm{H} 9 \mathrm{c} 2$ cells to $\mathrm{CoCl}_{2}$ and SGD.

Cell viability assay. Cell viability was detected by the CCK-8 kit. H9c2 cells were cultured in 96-well plates at a density of 5,000 cells/well. When the cells were $\sim 70 \%$ fused, the indicated treatments were performed. After the treatments, $10 \mu 1$ CCK-8 solution was added into each well and the plates were incubated for $3 \mathrm{~h}$. The absorbance at $450 \mathrm{~nm}$ was measured with a microplate reader (Molecular Devices, Sunnyvale, CA, USA). A mean optical density (OD) of 4 wells in each group was used to calculate percentage of cell viability using the formula: percentage of cell viability = OD treatment group/OD control group x $100 \%$. Experiments were performed in triplicate.

Western blotting. At the end of the treatments, the $\mathrm{H} 9 \mathrm{c} 2$ cells were harvested and lysed with ice-cold cell lysis solution and the homogenate was centrifuged at 10,000 $\mathrm{x} g$ for $12 \mathrm{~min}$ at $4^{\circ} \mathrm{C}$. Total protein in the supernatant was quantified using a BCA protein assay kit. Total protein $(20 \mu \mathrm{g})$ from each sample was separated by $12 \%$ SDS-PAGE. The protein in the gel was transferred into polyvinylidene difluoride (PVDF) membrane. The membrane was blocked with 5\% fat-free milk in TBS-T for $2 \mathrm{~h}$ at room temperature, and then incubated with the primary antibodies specific to HSP90 $(1: 2,000)$, or $\beta$-actin $(1: 8,000)$ with gentle agitation at $4^{\circ} \mathrm{C}$ overnight, followed by horseradish peroxidase-conjugated secondary antibodies for $60 \mathrm{~min}$ at room temperature. After three washes with TBS-T, the membranes were developed using an enhanced chemiluminescence and exposed to X-ray film. To quantify the protein expression, the X-ray film was scanned and analyzed using Image J 1.46i software (National Institutes of Health, USA).

Measurement of intracellular reactive oxygen species (ROS) level. Intracellular ROS was determined by the oxidative conversion of cell-permeable DCFH-DA to fluorescent DCF. $\mathrm{H} 9 \mathrm{c} 2$ cells were cultured on a slide in DMEM-F12 medium. After the indicated treatments, the slides were washed twice with phosphate-buffered saline (PBS). DCFH-DA solution in serum-free medium was added at a concentration of $10 \mu \mathrm{M}$ and co-incubated with $\mathrm{H} 9 \mathrm{c} 2$ cells at $37^{\circ} \mathrm{C}$ for $60 \mathrm{~min}$. The slides were washed three times, and DCF fluorescence was measured over the entire field of vision using a fluorescent microscope connected to an imaging system (BX50-FLA; Olympus). Mean fluorescence intensity (MFI) from three random fields was analyzed using Image J 1.46i software and the MFI of DCF represented the amount of ROS.

Measurement of mitochondrial membrane potential (MMP). MMP was monitored with a fluorescent dye Rh123, a cell-permeable cationic dye that preferentially enters into mitochondria based on the highly negative MMP. Depolarization of MMP results in the loss of Rh123 from mitochondria and a decrease in intracellular green fluorescence. Rh123 $(100 \mathrm{mg} / \mathrm{l})$ was added into cell cultures for $30 \mathrm{~min}$ at $37^{\circ} \mathrm{C}$ and fluorescence was measured over the entire field of vision with a fluorescent microscope connected to an imaging system (BX50-FLA; Olympus). MFI of Rh123 from three random fields was analyzed using Image J $1.46 \mathrm{i}$ software and MFI was regarded as an index of the level of MMP.

Statistical analysis. Data were shown as the mean \pm SE. The assessment of differences between groups was analyzed by Tukey's test of one-way ANOVA with OriginPro 8.0 (OriginLab Corporation, Northampton, MA, USA). $\mathrm{P}<0.05$ was considered to indicate statistical significance. 


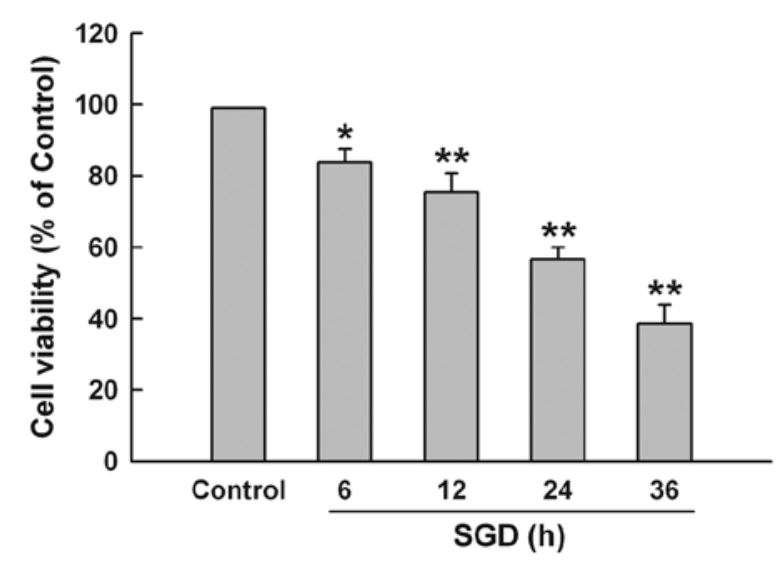

Figure 1. Cytotoxic effect of SGD on cell viability is shown. H9c2 cells were incubated in serum- and glucose-free medium for $6,12,24$ and $36 \mathrm{~h}$, respectively. The CCK- 8 assay was performed to examine cell viability. Data are shown as the mean $\pm \mathrm{SE}, \mathrm{n}=3 .{ }^{*} \mathrm{P}<0.05,{ }^{* *} \mathrm{P}<0.01$ vs. control group.
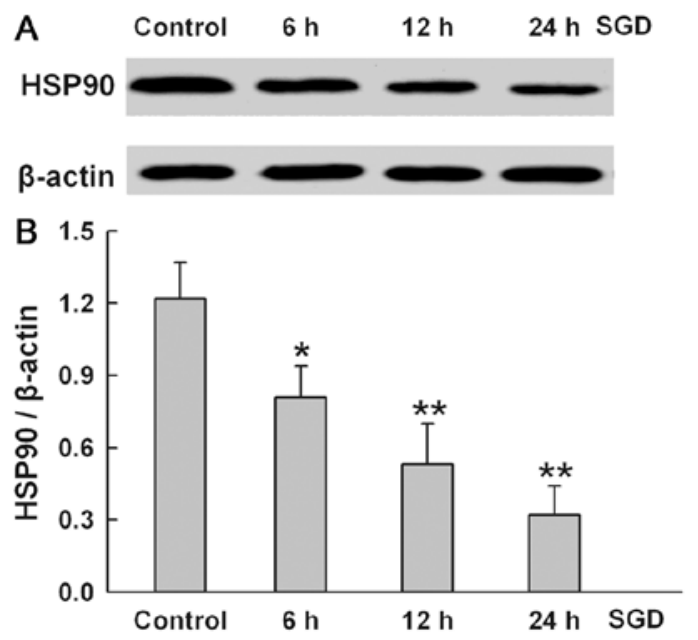

Figure 2. Attenuation of HSP90 expression by SGD in H9c2 cells is shown. (A) H9c2 cells were incubated in serum- and glucose-free medium for 6,12 and $24 \mathrm{~h}$, respectively. Expression of HSP90 was detected by western blotting assay. (B) Densitometric analysis for the changes in HSP90 expression in (A). Data are shown as the mean $\pm \mathrm{SE}, \mathrm{n}=3$. ${ }^{*} \mathrm{P}<0.05,{ }^{* *} \mathrm{P}<0.01$ vs. control group.

\section{Results}

SGD time-dependently enhances cytotoxicity in H9c2 cells. To test the effect of SGD on cytotoxicity in H9c2 cells, the CCK-8 assay was performed. Fig. 1 shows that SGD obviously induced cytotoxicity, leading to a time-dependent decrease in cell viability. Cell survival was decreased to $56.7 \pm 3.3 \%$ by $24 \mathrm{~h}$ of incubation in serum- and glucose-free medium. Therefore, $24 \mathrm{~h}$ of SGD was used as an effective injury time in the subsequent experiments.

SGD downregulates the expression of HSP9O in H9c2 cells. To determine the effect of SGD on HSP90 expression, the changes in HSP90 expression were tested in serum- and glucose-deprived $\mathrm{H} 9 \mathrm{c} 2$ cells for the indicated times $(6,12$ and $24 \mathrm{~h}$ ), respectively. SGD attenuated HSP90 expression in a

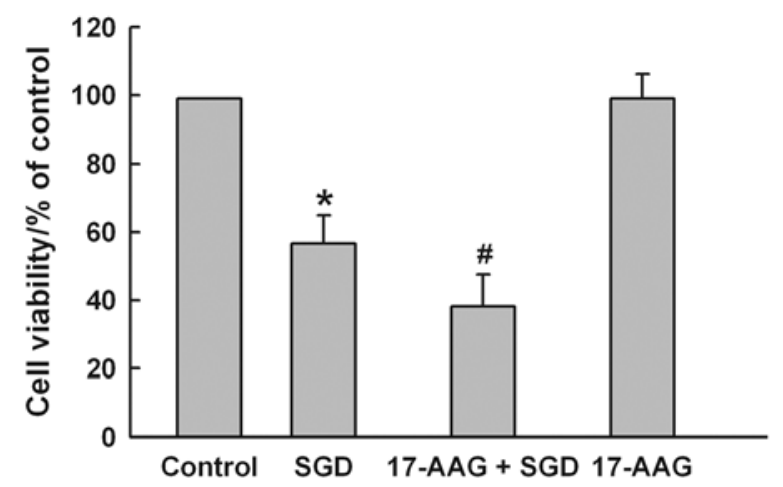

Figure 3. Effect of HSP90 inhibitor on cytotoxicity induced by SGD in H9c2 cells is shown. The cells were incubated in serum- and glucose-free medium for $24 \mathrm{~h}$. To inhibit HSP90, the cells were pretreated with $2 \mu \mathrm{M} 17-\mathrm{AAG}$, a selective inhibitor of HSP90, for $60 \mathrm{~min}$ prior to SGD. Cell viability was examined by the CCK- 8 assay. Data are shown as the mean $\pm \mathrm{SE}, \mathrm{n}=3$. ${ }^{*} \mathrm{P}<0.01$ vs. control group; ${ }^{\#} \mathrm{P}<0.05$ vs. SGD group.

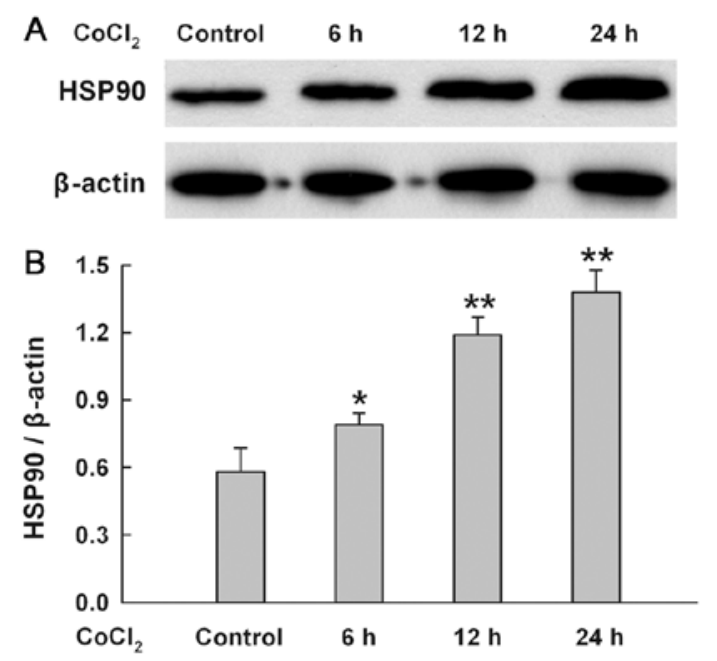

Figure 4. Effect of $\mathrm{CoCl}_{2}$ on expression of HSP90 in $\mathrm{H} 9 \mathrm{c} 2$ cells. $\mathrm{H} 9 \mathrm{c} 2$ cells were exposed to $100 \mu \mathrm{M} \mathrm{CoCl}_{2}$ for 6, 12 and $24 \mathrm{~h}$, respectively. (A) Expression of HSP90 was tested by western blotting and (B) quantified by densitometric analysis using ImageJ 1.46i software. A time-dependent increase in HSP90 expression was observed. Data are shown as the mean $\pm \mathrm{SE}, \mathrm{n}=3$. ${ }^{*} \mathrm{P}<0.05$, ${ }^{* *} \mathrm{P}<0.01$ vs. control group.

time-dependent manner, suggesting that the downregulation of HSP90 expression may be one of the mechanisms involved in SGD-induced injury in the H9c2 cells (Fig. 2). The results of subsequent experiments showed that pretreatment of the cells with $2 \mu \mathrm{M}$ 17-AAG, a selective inhibitor of HSP90, for $60 \mathrm{~min}$ before SGD for $24 \mathrm{~h}$ markedly aggravated SGD-induced cytotoxicity, evidenced by a further decrease in cell viability (Fig. 3). However, 17-AAG alone did not alter cell viability in $\mathrm{H} 9 \mathrm{c} 2$ cells. These results showed that HSP90 may be one of the molecular defensive mechanisms against SGD-induced injury in $\mathrm{H} 9 \mathrm{c} 2$ cells.

$\mathrm{CoCl}_{2}$ time-dependently upregulates the expression of HSP9O in $\mathrm{H} 9 \mathrm{c} 2$ cells. As shown in Fig. 4, when H9c2 cells were treated with $100 \mu \mathrm{M} \mathrm{CoCl}_{2}$ for 6-24 h, a time-dependent increase in HSP90 expression was found. 

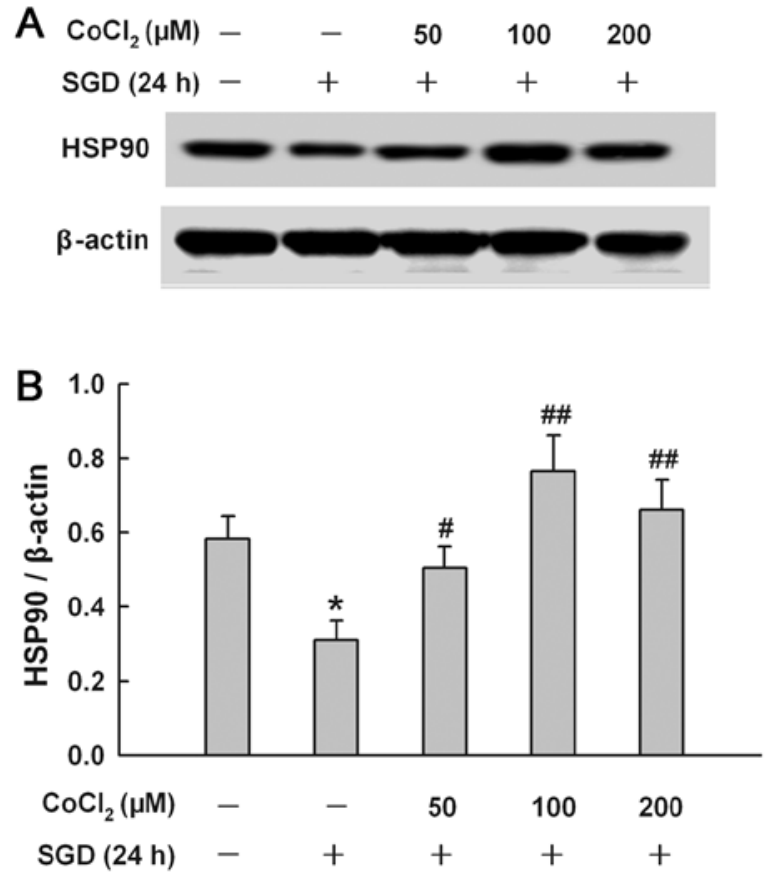

Figure 5. Down-regulatory effect of $\mathrm{CoCl}_{2}$ on the inhibition of HSP90 expression by SGD in $\mathrm{H} 9 \mathrm{c} 2$ cells. $\mathrm{H} 9 \mathrm{c} 2$ cells were treated with $\mathrm{CoCl}_{2}$ at concentrations of 50, 100 and $200 \mu \mathrm{M}$ for $24 \mathrm{~h}$ in the presence of SGD, respectively. (A) HSP90 expression was detected by western blotting and (B) quantified by densitometric analysis using ImageJ 1.46i software. Data are shown as the mean $\pm \mathrm{SE}, \mathrm{n}=3$. ${ }^{*} \mathrm{P}<0.01$ vs. control group; ${ }^{\#} \mathrm{P}<0.05,{ }^{\# \#} \mathrm{P}<0.01$ vs. SGD group.

$\mathrm{CoCl}_{2}$ reduces the inhibitory effect of $S G D$ on the expression of HSP9O in H9c2 cells. To explore the effect of chemical hypoxia on the SGD-induced inhibition of HSP90 expression, $\mathrm{H} 9 \mathrm{c} 2$ cells were treated with $\mathrm{CoCl}_{2}$ at concentrations ranging from 50 to $200 \mu \mathrm{M}$ for $24 \mathrm{~h}$ in the presence of SGD, respectively. Fig. 5 shows that co-treatment with $\mathrm{CoCl}_{2}$ at 50,100 and $200 \mu \mathrm{M}$ inhibited the downregulation of the SGD-induced HSP90 expression. A maximal inhibitory effect of $\mathrm{CoCl}_{2}$ was observed at $100 \mu \mathrm{M}$.

HSP90 contributes to the cytoprotection at low concentrations of $\mathrm{CoCl}_{2}$ against $\mathrm{SGD}$-induced cytotoxicity in $\mathrm{H} 9 \mathrm{c} 2$ cells. $\mathrm{CoCl}_{2}$ at different concentrations had different effects on SGD-induced cytotoxicity in H9c2 cells (Fig. 6A). Treatment of cells with low concentrations (50, 100 and $200 \mu \mathrm{M}$ ) obviously protected against SGD-induced cytotoxicity, leading to an increase in cell viability. These concentrations demonsrated a maximum cytoprotective effect of $\mathrm{CoCl}_{2}$ at $100 \mu \mathrm{M}$, which alone did not affect cell viability (data not shown). Therefore, $100 \mu \mathrm{M}$ of $\mathrm{CoCl}_{2}$ was used as an effective protection concentration in the subsequent experiments. These results suggest that sublethal chemical hypoxia treatment is protective against ischemia-like injury.

To investigate the role of HSP90 in the cytoprotective effect of $\mathrm{CoCl}_{2}$ at low concentrations against SGD-induced injury, $\mathrm{H} 9 \mathrm{c} 2$ cells were pretreated with $2 \mu \mathrm{M}$ 17-AAG, a selective inhibitor of HSP90, for 60 min prior to the co-treatment of $100 \mu \mathrm{M} \mathrm{CoCl}_{2}$ with SGD for $24 \mathrm{~h}$. Fig. 6B shows that cell treatment with $100 \mu \mathrm{M} \mathrm{CoCl}_{2}$ considerably reduced SGD-induced cytotoxicity, evidenced by an increase in cell
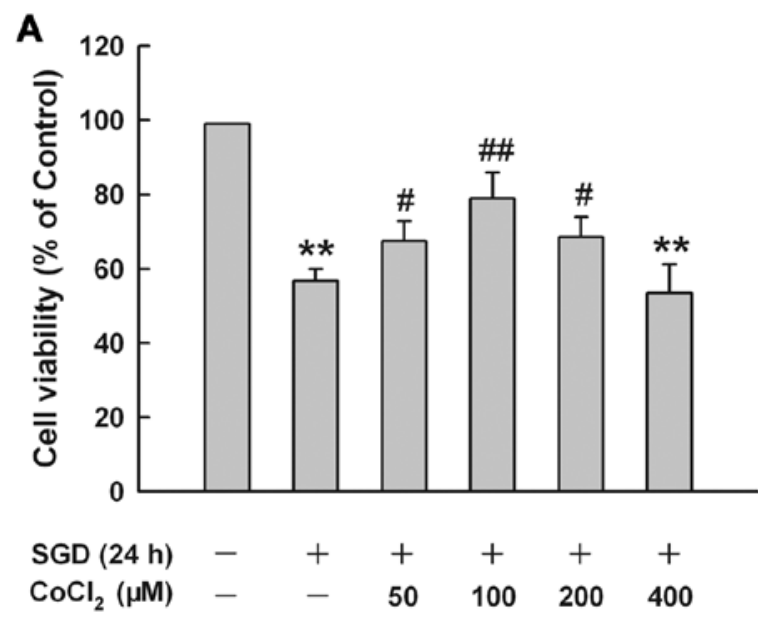

B

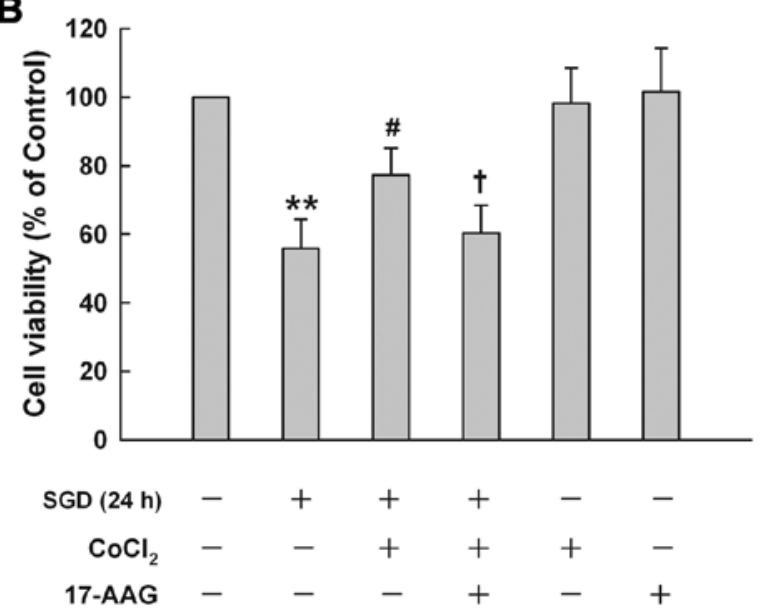

Figure 6. Involvement of HSP90 in the cytoprotection of low concentration $\mathrm{CoCl}_{2}$ from SGD-induced cytotoxicity in $\mathrm{H} 9 \mathrm{c} 2$ cells is shown. (A) H9c2 cells were treated with $\mathrm{CoCl}_{2}$ at the indicated concentrations for $24 \mathrm{~h}$ in the presence of SGD. (B) H9c2 cells were preconditioned with $2 \mu \mathrm{M}$ 17-AAG, a selective inhibitor of HSP90, for 60 min before co-treatment of $100 \mu \mathrm{M}$ $\mathrm{CoCl}_{2}$ and SGD for $24 \mathrm{~h}$. The CCK-8 assay was performed to detect cell viability. Data are shown as the mean $\pm \mathrm{SE}, \mathrm{n}=3$. ${ }^{* *} \mathrm{P}<0.01$ vs. control group; ${ }^{\#} \mathrm{P}<0.05,{ }^{\# \#} \mathrm{P}<0.01$ vs. SGD group; ${ }^{\dagger} \mathrm{P}<0.05$ vs. $\mathrm{CoCl}_{2}+\mathrm{SGD}$ group.

viability. However, this cytoprotection of $\mathrm{CoCl}_{2}$ treatment was reduced by $17-\mathrm{AAG}$ pretreatment, suggesting that HSP90 is involved in the protective effect of sublethal chemical hypoxia against cardiac toxicity induced by SGD in H9c2 cells. However, $2 \mu \mathrm{M}$ 17-AAG alone did not alter cell viability.

HSP90 participates in the antioxidant effect induced by a low concentration of $\mathrm{CoCl}_{2}$ in $\mathrm{H} 9 \mathrm{c} 2$ cells. A more recent study showed that a high concentration $(600 \mu \mathrm{M})$ of $\mathrm{CoCl}_{2}$ induces ROS generation in $\mathrm{H} 9 \mathrm{c} 2$ cells (17). Of note, we found that $\mathrm{CoCl}_{2}$ at $100 \mu \mathrm{M}$ reduced SGD-induced ROS generation, manifesting a decrease in DCF-derive fluorescence (an index of ROS level) (Fig. 7Ac). However, the antioxidant effect of $100 \mathrm{M} \mathrm{CoCl}_{2}$ was markedly suppressed by the inhibition of HSP90 with 17-AAG at $2 \mu \mathrm{M}$ (Fig. 7Ad). Alone, $100 \mu \mathrm{M}$ $\mathrm{CoCl}_{2}$ or $2 \mu \mathrm{M}$ 17-AAG did not alter the basal level of ROS. These results indicated that the antioxidant effect of low concentrations of $\mathrm{CoCl}_{2}$ may be associated with an upregulated HSP90 expression. 

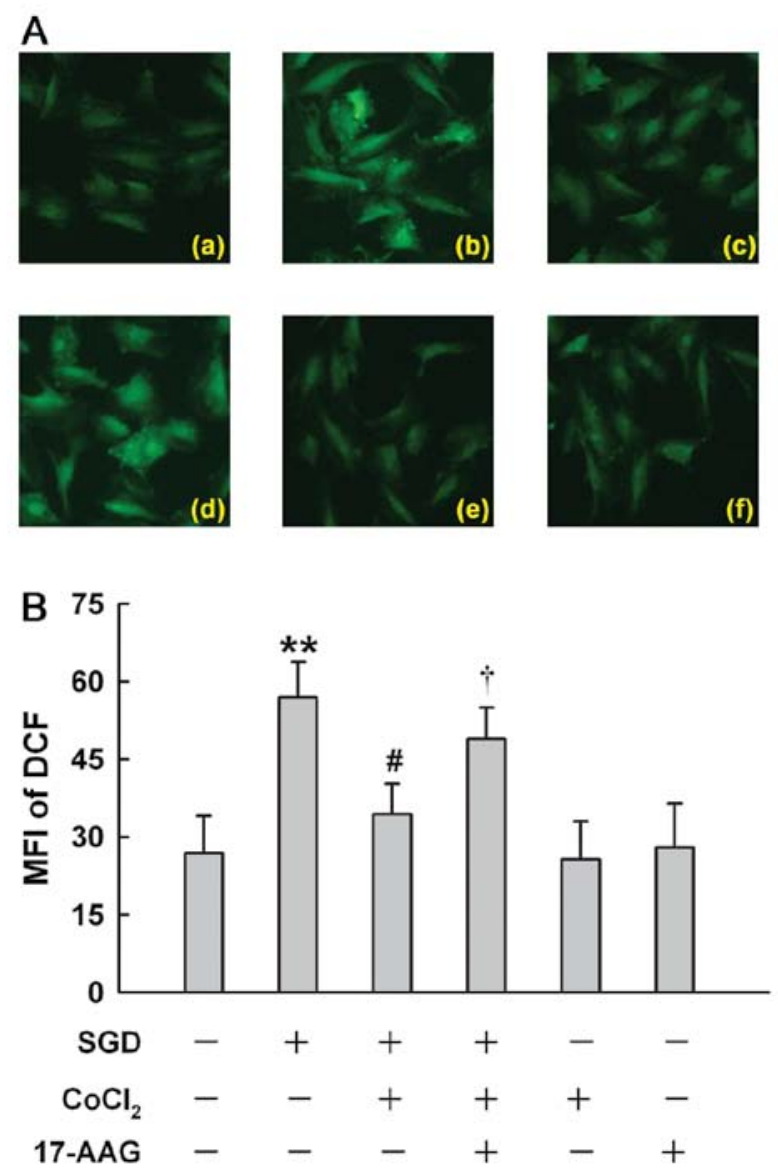

Figure 7. Contribution of HSP90 to the antioxidation of low concentration of $\mathrm{CoCl}_{2}$ in $\mathrm{H} 9 \mathrm{c} 2$ cells is shown. (A) DCFH-DA staining followed by photofluorography was used to detect the intracellular ROS level in $\mathrm{H} 9 \mathrm{c} 2$ cells. (a) Control group. (b) H9c2 cells subjected to SGD for 24 h. (c) H9c2 cells were treated with $100 \mu \mathrm{M} \mathrm{CoCl}_{2}$ for $24 \mathrm{~h}$ in the presence of SGD. (d) Cells were pretreated with $2 \mu \mathrm{M}$ 17-AAG for $60 \mathrm{~min}$ prior to the co-treatment of $100 \mu \mathrm{M} \mathrm{CoCl}_{2}$ and SGD for $24 \mathrm{~h}$. (e) Cells were treated with $100 \mu \mathrm{M} \mathrm{CoCl}_{2}$ for $24 \mathrm{~h}$. (f) Cells were treated with $2 \mu \mathrm{M}$ 17-AAG for $60 \mathrm{~min}$ followed by $24 \mathrm{~h}$ culture. (B) Quantitative analysis of MFI of DCF using ImageJ 1.46i software. Data were shown as the mean $\pm \mathrm{SE}, \mathrm{n}=3 .{ }^{* *} \mathrm{P}<0.01$ vs. control group; ${ }^{\#} \mathrm{P}<0.05$ vs. SGD group; ${ }^{\dagger} \mathrm{P}<0.05$ vs. $\mathrm{CoCl}_{2}+\mathrm{SGD}$ group.

HSP90 is associated with the mitochondrial protection induced by low concentrations of $\mathrm{CoCl}_{2}$ in $\mathrm{H} 9 \mathrm{c} 2$ cells. Fig. 8 shows that after $\mathrm{H} 9 \mathrm{c} 2$ cells were subjected to SGD for $24 \mathrm{~h}$, mitochondria were markedly damaged, leading to a decrease in the uptake of Rh123, demonstrating dissipation of MMP (Fig. 8Ab). The loss of MMP was reduced by treatment with $100 \mu \mathrm{M} \mathrm{CoCl}_{2}$ for $24 \mathrm{~h}$ (Fig. 8Ac). The inhibition of HSP90 by 17-AAG $(2 \mu \mathrm{M})$ pretreatment significantly depressed the mitochondrial protection induced by $\mathrm{CoCl}_{2}$, resulting in the severe loss of MMP, suggesting that low concentrations of $\mathrm{CoCl}_{2}$ provide mitochondrial protection by enhancing HSP90 expression.

\section{Discussion}

The important findings of this study are that co-treatment of low concentrations of $\mathrm{CoCl}_{2}$ with SGD provides cardioprotection against ischemia-like injury in H9c2 cells and that HSP90 contributes to the cardioprotective effect of sublethal chemical hypoxia from SGD-induced injury through its antioxidation
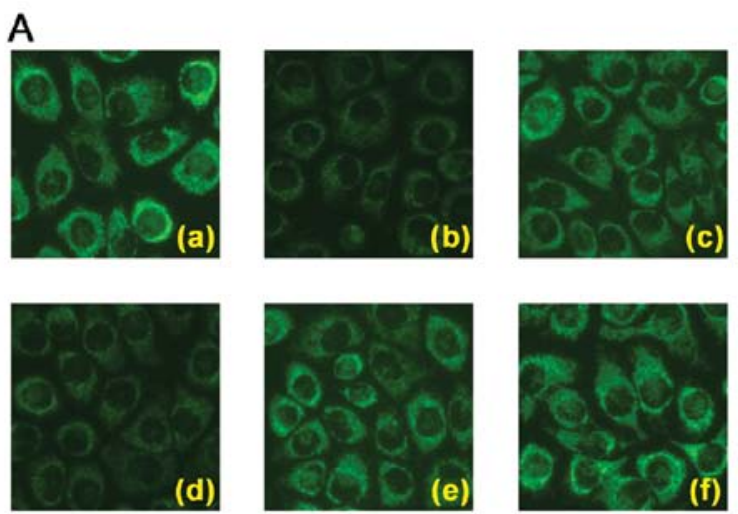

B

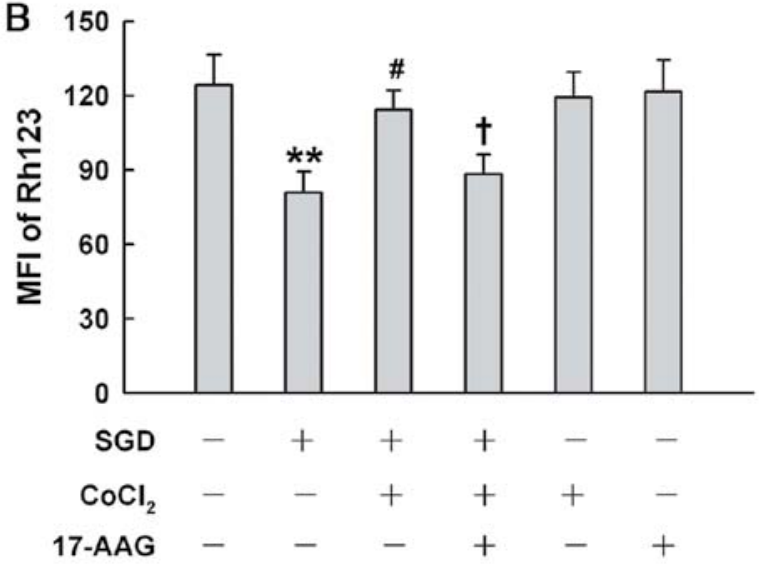

Figure 8 . The effect of HSP90 in mitochondrial protection induced by low concentration of $\mathrm{CoCl}_{2}$ in $\mathrm{H} 9 \mathrm{c} 2$ cells is shown. (A) Rh123 staining followed by photofluorography to MMP. (a) Control group. (b) H9c2 cells subjected to SGD for $24 \mathrm{~h}$. (c) Cells were treated with $100 \mu \mathrm{M} \mathrm{CoCl}_{2}$ for $24 \mathrm{~h}$ in the presence of SGD. (d) Cells were pretreated with $2 \mu \mathrm{M} 17-\mathrm{AAG}$ for $60 \mathrm{~min}$ prior to the co-treatment of $100 \mu \mathrm{M} \mathrm{CoCl}_{2}$ and SGD for $24 \mathrm{~h}$. (e) Cells were treated with $100 \mu \mathrm{M} \mathrm{CoCl}_{2}$ for $24 \mathrm{~h}$. (f) Cells were treated with $2 \mu \mathrm{M} 17-\mathrm{AAG}$ for 60 min followed by $24 \mathrm{~h}$ culture. (B) Quantitative analysis of MFI of Rh123 in (A) with the ImageJ 1.46i software. Data are shown as the mean $\pm \mathrm{SE}, \mathrm{n}=3$. ${ }^{* *} \mathrm{P}<0.01$ vs. control group; ${ }^{\#} \mathrm{P}<0.05$ vs. SGD group; ${ }^{\dagger} \mathrm{P}<0.05$ vs. $\mathrm{CoCl}_{2}+\mathrm{SGD}$ group.

and mitochondrial protection. The present study provides novel evidence to support the hypothesis that sublethal endogenous hypoxia may be one of the defensive mechanisms by which cardiomyocytes become more resistant to ischemiainduced injury and that cobalt, a traditional medicine, may have therapeutic efficacy for the treatment of ischemia-related cardiac diseases.

Previous studies have shown that pretreatment with $\mathrm{CoCl}_{2}$, a well-known hypoxia mimetic agent, offers cardioprotective effects, including attenuation of myocardial apoptosis (12) and improvement of cardiac contractile functions (11). Consistent with these studies $(11,12)$, in the present study, we found that co-treatment of $100 \mu \mathrm{M} \mathrm{CoCl}_{2}$, which does not damage $\mathrm{H} 9 \mathrm{c} 2$ cells, is able to protect against SGD-induced injury, leading to an increase in cell viability, a decrease in ROS generation and a preservation of MMP. Due to the unpredictability of hypoxia or ischemia timing, the clinical significance of hypoxia preconditioning is limited. Since co-treatment with $\mathrm{CoCl}_{2}$ has a similar cardioprotection as $\mathrm{CoCl}_{2}$ preconditioning, 
the administration of cobalt used in this study has potential clinical significance for the treatment of ischemia-related heart diseases. Furthermore, our results provide new data to demonstrate the inhibitory effect of cobalt on ischemia-like cardiac injury.

Based on our findings and those of previous studies (11,12,15-19), several possible mechanisms are responsible for the cardioprotective effect of low concentrations of $\mathrm{CoCl}_{2}$ : i) its antioxidant effect, by which $\mathrm{CoCl}_{2}$ is able to reduce SGD-induced ROS generation in $\mathrm{H} 9 \mathrm{c} 2$ cells Consistent with our findings, a previous study has shown that manganese-containing superoxide dismutase (SOD) and mitochondrial-targeted catalase significantly protects against cytotoxicity and the glucose deprivation-induced oxidative stress (20); ii) its mitochondrial protective effect, by which $\mathrm{CoCl}_{2}$ inhibits the SGD-induced dissipation of MMP. Similarly, cobalt has been shown to have direct action in preserving ATP in adult rat myocardium (21); iii) its enhancement effect on HIF-1 expression, by which $\mathrm{CoCl}_{2}$ is capable of protecting isolated mouse hearts against ischemia/reperfusion (I/R)-induced injury (22); iv) its upregulation effect on EPO, which is one of the target products of HIF-1. Cai et al (23) reported that hearts exposed to intermittent hypoxia or EPO are protected from I/R-induced injury. Previous studies have demonstrated the effectiveness of EPO in limiting apoptosis in rat cardiac myocytes $(24,25)$; v) its enhancing the levels of VEGF, by which low concentrations of $\mathrm{CoCl}_{2}$ improves cardiac contractile functions (11). VEGF is a potent angiogenic factor and its upregulation may facilitate tissue perfusion and oxygenation in hypoxia, an important adaptation to hypoxia; vi) its inductive effect of glucose transporters (GLUT). In the in vivo heart and cultured cardiac cells, both hypoxia and $\mathrm{Co}^{2+}$ rapidly induce GLUT-1 expression in the mRNA level $(26,27)$. The increased GLUT-1 is involved in improved cardiac contractile function in hypoxia-reoxygenation in rats treated with low concentrations of $\mathrm{CoCl}_{2}(11)$.

Besides the above six possible mechanisms underlying the cardioprotection of low concentrations of $\mathrm{CoCl}_{2}$, another important mechanism involves the activation of the oxygensensing mechanism by $\mathrm{CoCl}_{2}$, which may upregulate the expression of HSPs. HSPs are a family of protective proteins, which provide an endogenous cell defense mechanism against hostile environmental stress, including hypoxia and ischemia. Accumulating evidence has shown that the upregulation of HSP expression is capable of protecting cardiomyocytes from I/R-induced damage (28) or chemical hypoxia-triggered injury (17). Notably, $\mathrm{CoCl}_{2}$ is also able to upregulate the expression of HSP90 in H9c2 cells (17). Based on these previous studies $(17,29)$, we hypothesizes that HSP90 possibley contributes to the cardioprotective effect of co-treatment with low concentrations of $\mathrm{CoCl}_{2}$ from SGD-induced cardiomyocyte injury. In the present study, we initially observed that SGD downregulated the expression of HSP90 and that 17-AAG, a selective inhibitor of HSP90, significantly aggravated SGD-induced cytotoxicity in H9c2 cells, suggesting that HSP90 is an endogenous protective protein against SGD-induced injury. Secondly, we found that co-treatment with $100 \mu \mathrm{M} \mathrm{CoCl}_{2}$, not only enhanced the expression of HSP90, but also obviously blocked the inhibitory effect of SGD on HSP90 expression. Thirdly, examination into the roles of HSP90 in the cardioprotection of low concentrations of $\mathrm{CoCl}_{2}$ against SGD-induced injuries, including cytotoxicity, overproduction of ROS and dysfunction of mitochondria was conducted. The findings of the present study have shown that the inhibition of HSP90 by 17-AAG markedly blocked the reduction of cytotoxicity induced by $\mathrm{CoCl}_{2}$ at $100 \mu \mathrm{M}$, indicating the involvement of HSP90 in the cardioprotective effect of $\mathrm{CoCl}_{2}$ against SGD-triggered injury. Our results are comparable with those of a recent study whereby the inhibition of HSP90 by geldanamycin, an inhibitor of HSP90, or siRNA completely eliminates the protective effect of hypoxic pretreatment against prolonged hypoxia/reoxygenation-elicited damage in H9c2 cells (30). Yang et al (17) also reported that increased HSP90 expression participates in the cardioprotection induced by hydrogen sulfide $\left(\mathrm{H}_{2} \mathrm{~S}\right)$.

ROS is regarded as a toxic byproduct of aerobic metabolism following reoxygenation after periods of ischemia or hypoxia (31). Ahmad et al (20) indicated that mitochondrial ROS mediate glucose deprivation-induced cytotoxicity. In this study, it was shown that co-treatment with low concentrations of $\mathrm{CoCl}_{2}$ attenuated cytotoxicity, along with a decrease in ROS production, suggesting that co-treatment with $\mathrm{CoCl}_{2}$ is likely to induce antioxidants to reduce ROS generation. Findings of a more recent study have demonstrated the involvement of HSP90 in the antioxidant effect of $\mathrm{H}_{2} \mathrm{~S}$ (17). In agreement with this evidence, our data showed that 17-AAG significantly depressed $\mathrm{CoCl}_{2}$-induced inhibitory effect on the overproduction of ROS elicited by SGD in H9c 2 cells, demonstrating that HSP90 is involved in the antioxidant effect of $\mathrm{CoCl}_{2}$.

Mitochondria play a critical role in determining the cell fate (32) by regulating the mitochondrial permeability transition pore (PTP) and the release of a number of apoptotic factors. Cell death inhibition is accompanied by MMP preservation (17,33-35). Since antioxidants are able to inhibit the loss of MMP, the role of HSP90 in the $\mathrm{CoCl}_{2}$-induced cardioprotective effect may be associated with the preservation of mitochondrial function. In this study, co-treatment with $\mathrm{CoCl}_{2}$ considerably inhibited SGD-induced loss of MMP, and this mitochondrial protective function was blocked by the inhibition of HSP90 by 17-AAG. Our findings are supported by those of Yang et al (17) and are consistent with a recent finding that HSP90 is required for mitochondrial protein import for hydrophobic membrane proteins, especially under stress conditions (36).

Taken together, in the present study, we have demonstrated that chemical hypoxia-upregulated HSP90 expression contributes to the $\mathrm{CoCl}_{2}$-induced cardioprotective effect from SGD-triggered injury by depressing cytotoxicity and oxidative stress as well as preserving MMP. However, more experiments are required to elucidate the activation of the cardiac oxygensensing mechanism by $\mathrm{CoCl}_{2}$, in particular, the interaction between HIF-1 and HSP90.

\section{Acknowledgements}

The present study was supported by the Science and Technology Planning Project of Guangdong in China(nos. 2011B031800002 and 2011B080701051) and the Guangdong Natural Science Foundation (no. S2011010002620). 


\section{References}

1. Fandrey J: Hypoxia-inducible gene expression. Respir Physiol 101: 1-10, 1995.

2. Gleadle JM and Ratcliffe PJ: Hypoxia and the regulation of gene expression. Mol Med Today 4: 122-129, 1998.

3. Goldberg MA, Dunning SP and Bunn HF: Regulation of the erythropoietin gene: evidence that the oxygen sensor is a heme protein. Science 242: 1412-1415, 1988.

4. Semenza GL and Wang GL: A nuclear factor induced by hypoxia via de novo protein synthesis binds to the human erythropoietin gene enhancer at a site required for transcriptional activation. Mol Cell Biol 12: 5447-5454, 1992.

5. Semenza GL: $\mathrm{O}_{2}$-regulated gene expression: transcriptional control of cardiorespiratory physiology by HIF-1. J Appl Physiol 96: 1173-1177, 2004

6. Greijer AE, van der Groep P, Kemming D, et al: Up-regulation of gene expression by hypoxia is mediated predominantly by hypoxia-inducible factor 1 (HIF-1). J Pathol 206: 291-304, 2005.

7. Baird NA, Turnbull DW and Johnson EA: Induction of the heat shock pathway during hypoxia requires regulation of heat shock factor by hypoxia-inducible factor-1. J Biol Chem 281 : 38675-38681, 2006.

8. Huang Y, Du KM, Xue ZH, et al: Cobalt chloride and low oxygen tension trigger differentiation of acute myeloid leukemic cells: possible mediation of hypoxia-inducible factor-1alpha. Leukemia 17: 2065-2073, 2003.

9. Kim EJ, Yoo YG, Yang WK, et al: Transcriptional activation of HIF-1 by RORalpha and its role in hypoxia signaling. Arterioscler Thromb Vasc Biol 28: 1796-1802, 2008.

10. Lan A, Liao X, Mo L, et al: Hydrogen sulfide protects against chemical hypoxia-induced injury by inhibiting ROS-activated ERK1/2 and p38MAPK signaling pathways in PC12 cells. PLoS One 6: e25921, 2011.

11. Endoh H, Kaneko T, Nakamura $\mathrm{H}$, et al: Improved cardiac contractile functions in hypoxia-reoxygenation in rats treated with low concentration $\mathrm{Co}(2+)$. Am J Physiol Heart Circ Physiol 279: H2713-H2719, 2000.

12. Kerendi F, Kirshbom PM, Halkos ME, et al: Thoracic Surgery Directors Association Award. Cobalt chloride pretreatment attenuates myocardial apoptosis after hypothermic circulatory arrest. Ann Thorac Surg 81: 2055-2062, 2006.

13. Zhao ZQ, Corvera JS, Halkos ME, et al: Inhibition of myocardial injury by ischemic postconditioning during reperfusion: comparison with ischemic preconditioning. Am J Physiol Heart Circ Physiol 285: H579-H588, 2003.

14. Duckham JM and Lee HA: The treatment of refractory anaemia of chronic renal failure with cobalt chloride. Q J Med 45: 277-294, 1976.

15. Fisher JW and Langston JW: Effects of testosterone, cobalt and hypoxia on erythropoietin production in the isolated perfused dog kidney. Ann NY Acad Sci 149: 75-87, 1968.

16. Janda WE, Fried W and Gurney CW: Combined effect of cobalt and testosterone on erythropoiesis. Proc Soc Exp Biol Med 120: 443-446, 1965

17. Yang $\mathrm{Z}$, Yang $\mathrm{C}$, Xiao L, et al: Novel insights into the role of HSP90 in cytoprotection of $\mathrm{H}_{2} \mathrm{~S}$ against chemical hypoxiainduced injury in $\mathrm{H} 9 \mathrm{c} 2$ cardiac myocytes. Int J Mol Med 28 : 397-403, 2011.

18. Eyssen-Hernandez R, Ladoux A and Frelin C: Differential regulation of cardiac heme oxygenase-1 and vascular endothelial growth factor mRNA expressions by hemin, heavy metals, heat shock and anoxia. FEBS Lett 382: 229-233, 1996.
19. Katayose D, Isoyama S, Fujita $\mathrm{H}$, et al: Separate regulation of heme oxygenase and heat shock protein 70 mRNA expression in the rat heart by hemodynamic stress. Biochem Biophys Res Commun 191: 587-594, 1993.

20. Ahmad IM, Aykin-Burns N, Sim JE, et al: Mitochondrial $\mathrm{O}_{2}{ }^{*}-$ and $\mathrm{H}_{2} \mathrm{O}_{2}$ mediate glucose deprivation-induced stress in human cancer cells. J Biol Chem 280: 4254-4263, 2005.

21. Conrad CH, Brooks WW, Ingwall JS, et al: Inhibition of hypoxic myocardial contracture by Cobalt in the rat. J Mol Cell Cardiol 16: 345-354, 1984

22. Xi L, Taher M, Yin C, et al: Cobalt chloride induces delayed cardiac preconditioning in mice through selective activation of HIF-1alpha and AP-1 and iNOS signaling. Am J Physiol Heart Circ Physiol 287: H2369-H2375, 2004.

23. Cai Z, Manalo DJ, Wei G, et al: Hearts from rodents exposed to intermittent hypoxia or erythropoietin are protected against ischemia-reperfusion injury. Circulation 108: 79-85, 2003.

24. Parsa CJ, Matsumoto A, Kim J, et al: A novel protective effect of erythropoietin in the infarcted heart. J Clin Invest 112: 999-1007, 2003.

25. Calvillo L, Latini R, Kajstura J, et al: Recombinant human erythropoietin protects the myocardium from ischemia-reperfusion injury and promotes beneficial remodeling. Proc Natl Acad Sci USA 100: 4802-4806, 2003.

26. Sivitz WI, Lund DD, Yorek B, et al: Pretranslational regulation of two cardiac glucose transporters in rats exposed to hypobaric hypoxia. Am J Physiol 263: E562-E569, 1992.

27. Ybarra J, Behrooz A, Gabriel A, et al: Glycemia-lowering effect of cobalt chloride in the diabetic rat: increased GLUT1 mRNA expression. Mol Cell Endocrinol 133: 151-160, 1997.

28. Yin C, Xi L, Wang X, et al: Silencing heat shock factor 1 by small interfering RNA abrogates heat shock-induced cardioprotection against ischemia-reperfusion injury in mice. J Mol Cell Cardiol 39: 681-689, 2005.

29. Whitlock NA, Agarwal N, Ma JX, et al: HSP27 upregulation by HIF-1 signaling offers protection against retinal ischemia in rats. Invest Ophthalmol Vis Sci 46: 1092-1098, 2005.

30. Jiao JD, Garg V, Yang B, et al: Novel functional role of heat shock protein 90 in ATP-sensitive $\mathrm{K}^{+}$channel-mediated hypoxic preconditioning. Cardiovasc Res 77: 126-133, 2008.

31. McCord JM: Oxygen-derived free radicals in postischemic tissue injury. N Engl J Med 312: 159-163, 1985.

32. Green DR and Reed JC: Mitochondria and apoptosis. Science 281: 1309-1312, 1998.

33. Chen J, Tang XQ, Zhi JL, et al: Curcumin protects PC12 cells against 1-methyl-4-phenylpyridinium ion-induced apoptosis by Bcl-2-mitochondria-ROS-iNOS pathway. Apoptosis 11: 943-953, 2006.

34. Zhao K, Zhao GM, Wu D, et al: Cell-permeable peptide antioxidants targeted to inner mitochondrial membrane inhibit mitochondrial swelling, oxidative cell death, and reperfusion injury. J Biol Chem 279: 34682-34690, 2004.

35. Chen SL, Yang CT, Yang ZL, et al: Hydrogen sulphide protects H9c2 cells against chemical hypoxia-induced injury. Clin Exp Pharmacol Physiol 37: 316-321, 2010.

36. Young JC, Hoogenraad NJ and Hartl FU: Molecular chaperones Hsp90 and Hsp70 deliver preproteins to the mitochondrial import receptor Tom70. Cell 112: 41-50, 2003. 